\title{
Comparisons of Global Terrestrial Surface Water Datasets over 15 Years $\mathscr{0}$
}

\author{
BINH PHAM-DUC \\ Laboratoire d'Études du Rayonnement et de la Matière en Astrophysique et Atmosphères, CNRS, Observatoire de \\ Paris, Paris, France, and Space and Aeronautics Department, University of Science and \\ Technology of Hanoi, Hanoi, Vietnam
}

\section{CATHERINE PRigent AND FiliPe Aires}

Laboratoire d'Études du Rayonnement et de la Matière en Astrophysique et Atmosphères, CNRS, Observatoire de Paris, Paris, France

\section{FABRICE PAPA}

\author{
LEGOS, Université de Toulouse, IRD, CNES, CNRS, UPS, Toulouse, France, and Indo-French Cell for \\ Water Sciences, IRD-IISc-NIO-IITM, Indian Institute of Science, Bangalore, India
}

(Manuscript received 23 August 2016, in final form 5 January 2017)

\begin{abstract}
Continental surface water extents and dynamics are key information to model Earth's hydrological and biochemical cycles. This study presents global and regional comparisons between two multisatellite surface water extent datasets, the Global Inundation Extent from Multi-Satellites (GIEMS) and the Surface Water Microwave Product Series (SWAMPS), for the 1993-2007 period, along with two widely used static inundation datasets, the Global Lakes and Wetlands Database (GLWD) and the Matthews and Fung wetland estimates. Maximum surface water extents derived from these datasets are largely different: $\sim 13 \times 10^{6} \mathrm{~km}^{2}$ from GLWD, $\sim 5.3 \times 10^{6} \mathrm{~km}^{2}$ from Matthews and Fung, $\sim 6.2 \times 10^{6} \mathrm{~km}^{2}$ from GIEMS, and $\sim 10.3 \times 10^{6} \mathrm{~km}^{2}$ from SWAMPS. SWAMPS global maximum surface extent reduces by nearly $51 \%$ (to $\sim 5 \times 10^{6} \mathrm{~km}^{2}$ ) when applying a coastal filter, showing a strong contamination in this retrieval over the coastal regions. Anomalous surface waters are also detected with SWAMPS over desert areas. The seasonal amplitude of the GIEMS surface waters is much larger than the SWAMPS estimates, and GIEMS dynamics is more consistent with other hydrological variables such as the river discharge. Over the Amazon basin, GIEMS and SWAMPS show a very high time series correlation (95\%), but with SWAMPS maximum extent half the size of that from GIEMS and from previous synthetic aperture radar estimates. Over the Niger basin, SWAMPS seasonal cycle is out of phase with both GIEMS and MODIS-derived water extent estimates, as well as with river discharge data.
\end{abstract}

\section{Introduction}

Continental surface waters only cover a few percent of the land surface (Lehner and Döll 2004; Downing et al. 2006; Prigent et al. 2007), but they have a strong impact on the environment, as well as on human life (Vorosmarty et al. 2010). Surface freshwaters comprise

Supplemental information related to this paper is available at the Journals Online website: http://dx.doi.org/10.1175/ JHM-D-16-0206.s1.

Corresponding author e-mail: Binh Pham-Duc, pham.binh@ obspm.fr wetlands, rice paddies, rivers, lakes, reservoirs, and episodically inundated areas. Note that the definition of wetlands varies with applications and there is not an overall consensus on the subject (e.g., Reichhardt 1995). Surface waters play a key role in the biogeochemical and hydrological cycles, in biodiversity, and in climate variability. They show very diverse natures, from wetlands to inundated urban areas or rice paddies, associated with different dynamics from the tropics to the boreal regions. Wetlands are considered one of the most biologically diverse of all ecosystems since they support plant and wild animal species during important states of their life cycles. They are the world's largest natural source of methane $\left(\mathrm{CH}_{4}\right)$, and they provide about one-third of the total 
global emission $\left(\sim 165 \mathrm{Tg} \mathrm{yr}^{-1}\right.$; Bousquet et al. 2006; Bridgham et al. 2013; Wania et al. 2013). Consequently, monitoring surface freshwater extent and dynamics is a high priority in water management and climate research (e.g., Alsdorf et al. 2007).

Nevertheless, our understanding about the global distribution of the surface waters and their dynamics is still limited, with only a few datasets providing information at the global scale. Efforts have been made to collect information on water surfaces to produce static maps of surface waters, for example, the Global Lakes and Wetlands Database (GLWD) from Lehner and Döll (2004) or the Matthews and Fung (1987) wetland dataset. These maps are representative of the maximum surface water extent, and they do not provide any information on the temporal dynamics. Satellite observations in the visible, infrared, or microwave domains have the potential to detect surface water extent and their variations (Verpoorter et al. 2014; Yamazaki et al. 2015; Mueller et al. 2016; Feng et al. 2016), with different degrees of success depending on the environments. Optical and near-infrared satellite measurements provide good spatial resolutions but are limited by their inability to penetrate clouds and dense vegetation. Microwaves, passive or active, have the ability to penetrate clouds and vegetation, to a certain extent. With synthetic aperture radar (SAR) data, high spatial resolution is obtained, but global products describing the surface water dynamics are not available yet. Passive microwave observations have long been used to detect surface water extents, but used alone, it is difficult to disentangle the vegetation contribution from the measured signal. Prigent et al. (2016) propose a review on the use of different satellite techniques to monitor surface water, discussing in detail their advantages and limitations regarding the diverse applications.

These considerations lead to the conclusion that there is currently not a unique satellite technique for detecting surface water dynamics globally from tropical to boreal regions. In the following, surface waters will include all surface water types (wetlands, rice paddies, rivers, lakes, reservoirs, and episodically inundated areas), as the satellite observations cannot distinguish between the different natures of the surface water. A multisatellite methodology has been developed to derive surface water extent and dynamics at the global scale, benefiting from complementary strengths of satellite observations in the visible, passive, and active microwaves (Prigent et al. 2001, 2007, 2012; Papa et al. 2010): the Global Inundation Extent from Multi-Satellites (GIEMS). More recently, the Surface Water Microwave Product Series (SWAMPS) has been produced, also based on the merging of passive and active microwave satellite observations (Schroeder et al. 2015). Long time series of global surface water estimates are necessary today to analyze the changes in the wetland-related methane emission (e.g., Melton et al. 2013; Wania et al. 2013), and climate modelers are in strong need of wetland extent information to understand the methane variability over past decades (Ringeval et al. 2010; Pison et al. 2013) for a better prediction of its evolution in the upcoming decades. GIEMS has been extensively evaluated and is limited to 1993-2007 (time extension is underway). SWAMPS is a recent dataset that extends from 1992 to 2013. They have a similar spatial resolution $\left(\sim 0.25^{\circ} \times\right.$ $\left.0.25^{\circ}\right)$. As these two datasets are currently the only global surface water datasets with monthly time series, a thorough comparison of these estimates is needed for the user community.

Here, global surface water datasets are systematically and objectively compared, including the two multisatellite databases, GIEMS and SWAMPS, along with two static datasets. The analysis covers the common period of the two satellite-derived products (19932007), and both the spatial and temporal variabilities of the databases are studied. The surface water datasets are described in section 2. Global and regional comparisons are described and discussed in section 3. A discussion is presented in section 4 , and section 5 concludes this study.

\section{Data}

\section{a. GIEMS}

GIEMS was the first global surface water dataset that provided monthly distribution of wetland and surface water extent (including lakes, rivers, and irrigated agriculture). GIEMS data cover the period 1993-2007 and are mapped on an equal-area grid of $0.25^{\circ} \times 0.25^{\circ}$ spatial resolution at the equator (pixels of $773 \mathrm{~km}^{2}$ ). Inundated surfaces were detected and their extent was estimated by the method developed by Prigent et al. (2001, 2007, 2012). Global monthly inundation maps are derived from daily data of the following satellite observations: 1) passive microwave emissivity from the Special Sensor Microwave Imager (SSM/I), 2) active microwave backscatter coefficients from the scatterometer on board the European Remote-Sensing (ERS) satellite, and 3) the normalized difference vegetation index (NDVI) derived from visible and near-IR reflectances of the Advanced Very High Resolution Radiometer (AVHRR). Instead of directly using the brightness temperatures from the passive microwave instruments, surface emissivities are calculated to avoid modulation of the signal by atmospheric effects and surface temperature variations (Prigent et al. 2006). Passive microwave emissivities 
from SSM/I are primarily used to detect inundation of the land surface while active microwave backscatter is used to assess the vegetation contribution to the passive microwave signal. NDVI information is necessary to distinguish between bare surfaces and inundated surfaces in semiarid regions where they can produce similar passive microwave signatures. Because of the lack of continuity and consistency in the ERS and AVHRR products, the current version of GIEMS uses monthlymean climatology of ERS and AVHRR, calculated over 1993-2000. Other solutions were carefully tested, such as using other instruments like QuikSCAT instead of ERS, but this was not satisfactory (Papa et al. 2010). The snow-covered areas are filtered out using the National Snow and Ice Data Center (NSIDC) dataset (Brodzik and Armstrong 2013; http://nsidc.org/data/NSIDC0046). Inland seas (Caspian Sea and Aral Sea), big lakes (e.g., Great Lakes in North America), and coastal pixels (possibly contaminated by radiation from the ocean because of the large microwave fields of view) were also carefully suppressed from the GIEMS data. GIEMS has been thoroughly evaluated by comparison with static surface water databases, and its consistency with other hydrological information (e.g., precipitation and river height) has been assessed (Papa et al. 2006, 2007, 2008a, 2010). Recent works have been performed to downscale GIEMS using ancillary high-resolution data. GIEMS-D15 has a 15-arc-s resolution (nearly $500 \mathrm{~m}$ at the equator) for three different temporal states of the inundation extent (Fluet-Chouinard et al. 2015). First, the original 12-yr time series of GIEMS (19932004) were aggregated to get mean annual minimum, mean annual maximum, and long-term maximum at the pixel level. Second, GLWD data (Lehner and Döll 2004) were added to supplement missing data or to correct GIEMS underestimation for low water fraction. Finally, a global inundation probability map derived from the HydroSHEDS dataset (Lehner et al. 2008) was used to downscale GIEMS from the original resolution to 15 arc s (Fluet-Chouinard et al. 2015). In this project, we averaged GIEMS-D15 to the GIEMS grid $\left(0.25^{\circ}\right.$ at the equator) for comparison with the other datasets. More recently, a new version (GIEMS-D3) at 3-arc-s resolution (Aires et al. 2017) has been produced with an improved downscaling scheme.

\section{b. SWAMPS}

SWAMPS is a daily global surface water dataset, mapping open water areas and water under low-density vegetation, for the period 1992-2013 (Schroeder et al. 2015 ), on an equal-area grid of $25 \mathrm{~km}$ resolution at the equator (similar to GIEMS). It is derived from combined passive and active microwave observations: SSM/I and the Special Sensor Microwave Imager/Sounder (SSMI/S) for the passive microwave and the backscatter coefficients from ERS, QuikSCAT, and the Advanced Scatterometer (ASCAT). The microwave polarization difference index (MPDI), the ratio of the difference between the brightness temperatures in the two orthogonal polarizations over their sum, is the main indicator to detect the water bodies in this methodology. Backscatter coefficients from the ERS $(5 \mathrm{GHz})$, QuikSCAT $(10 \mathrm{GHz})$, and ASCAT (5 GHz) satellites are used to reduce the vegetation effect on the MPDI. The three instruments do not observe with the same angles and frequencies, and ad hoc corrections are performed to limit the effects of the changes on the time series (Schroeder et al. 2015). Snow cover and frozen ground are filtered using the method of Grody and Basist (1996) and Chang et al. (1987). Daily global SWAMPS data were averaged to obtain monthly global SWAMPS estimates at $0.25^{\circ} \times 0.25^{\circ}$ for comparison with the other datasets.

\section{c. GLWD}

GLWD is a global open water and wetland dataset developed by Lehner and Döll (2004). The dataset is derived from the combination of a variety of existing maps and information. Among these, the Digital Chart of the World (DCW) of the Environmental System Research Institute (ESRI) was the main source map to identify lakes and reservoirs. GLWD is not a satellite product, but a static map with three data levels: GLWD-1, GLWD-2, and GLWD-3. The GLWD-3 data used here include three main types of open water (rivers, lakes, and reservoirs) and nine different natural wetland classes in the form of a global raster map at 30-s resolution. For each wetland category $(50 \%-100 \%, 25 \%-50 \%$, and $0 \%-25 \%$ ) the average value (i.e., $75 \%, 37.5 \%$, and $12.5 \%$ ) is used. GLWD is designed to represent the maximum level of surface water extent regionally and globally. GLWD has been used extensively and compared favorably with different satellite-based land-cover datasets (Nakaegawa 2012). For comparison with the other datasets, GLWD is aggregated to the GIEMS grid.

\section{d. Other ancillary datasets}

Matthews and Fung (1987) wetland fractions come from aeronautical charts, the information for which is more likely acquired during warm seasons of maximum flooding (Matthews and Fung 1987). It is a static dataset on a $1^{\circ}$ regular grid. It has been extensively used in the past by climate groups to estimate the methane emission from wetlands.

Satellite products such as GIEMS and SWAMPS detect all surface water, including inundated areas 

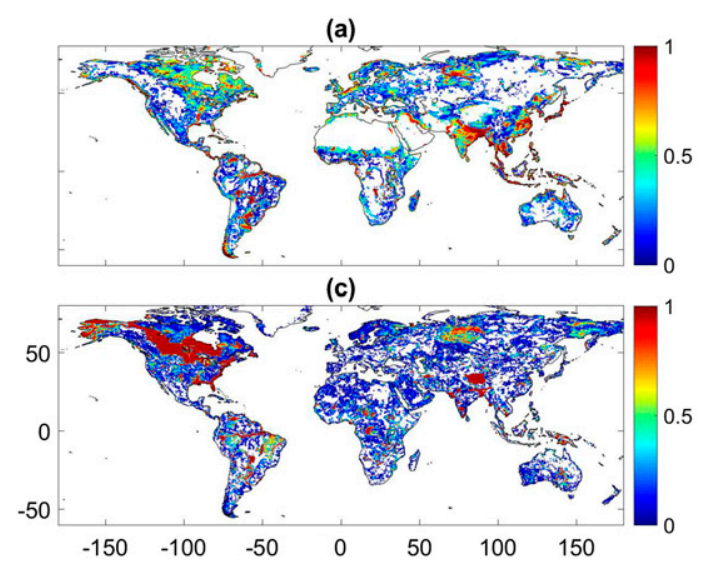

FIG. 1. Global maps of fractional surface water for different datasets on the equal-area grid at $0.25^{\circ} \times 0.25^{\circ}$ at the equator (773 $\mathrm{km}^{2}$ pixels). (a) GIEMS long-term monthly-mean max over 1993-2007, (b) original SWAMPS longterm monthly-mean max over 1993-2007, (c) GLWD, and (d) SWAMPS long-term monthly-mean max over 19932007 after coastal filtering.

associated with cultivation (such as the rice paddies in Asia) that are not accounted for in GLWD or in the Matthews and Fung (1987) wetland dataset. The global monthly irrigated and rain-fed crop areas (MIRCA) around the year 2000 (Portmann et al. 2010) provide information about irrigated and rain-fed agriculture globally. Irrigated rice is inundated during most of its growing season, and the MIRCA dataset provides an estimate of these inundated surfaces that are especially important in Asia (Adam et al. 2010). MIRCA is averaged from the 5-arc-min resolution to the common $0.25^{\circ}$-resolution grid.

River discharge data in some important basins of the world (e.g., Amazon, Orinoco, Niger, Mississippi, Congo, and $\mathrm{Ob}$ ) were collected as an ancillary source of information to compare with time series of the surface water datasets. In the present study, we show the comparisons with river discharge for three basins we focused on (Amazon, Niger, and Ob Rivers). For the Amazon River, we use the in situ monthly discharges observed at Obidos, Brazil, which is the closest gauge to the mouth of the river $(\sim 800 \mathrm{~km}$ from the ocean), and for which data are available for 1993-2007 at the Observation Service for the Geodynamical, Hydrological and Biogeochemical Control of Erosion/Alteration and Material Transport in the Amazon, Orinoco, and Congo basins (SO HYBAM) website (http://www.ore-hybam. org/). Daily river discharge at the Lokoja gauge (19982005) is used to get the monthly river discharge data for the Niger basin. The data are collected from the Global Runoff Data Centre (GRDC; http://www.bafg.de/ GRDC/EN/Home/homepage_node.html). Over the $\mathrm{Ob}$ River, we use the in situ records from the Russian Hydrometeorological Service that are available on

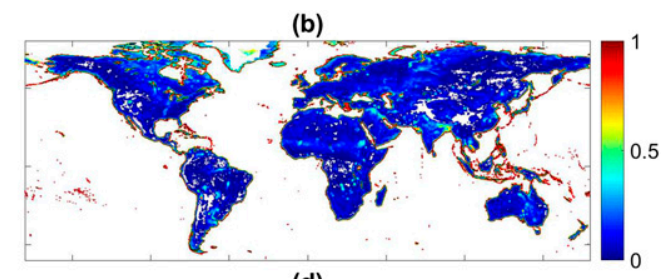

(d)

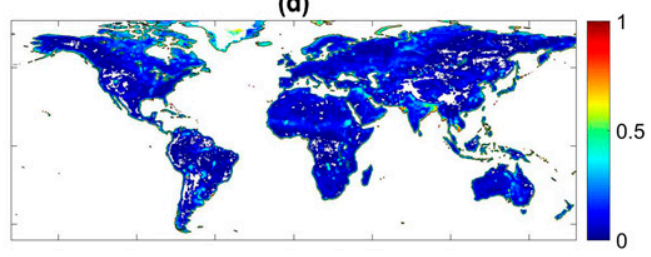

a monthly basis until 2004 in the archives of the R-Arctic project (http://www.r-arcticnet.sr.unh.edu/ v4.0/index.html).

\section{Comparisons of the surface water datasets}

The satellite-derived surface water datasets are compared over their common period 1993-2007, first globally and then at a basin scale. The 23 largest river basins in the world have been analyzed. However, the results are presented only for three basins located in contrasted types of environments: the Amazon basin in the tropics, the Niger basin in a semiarid area, and the Ob basin in the boreal region. The comparison is also systematically performed with the two static datasets previously described: GLWD and the Matthews and Fung (1987) dataset.

\section{a. Global comparisons}

Figure 1a shows the GIEMS long-term monthly-mean maximum inundation for each pixel over 1993-2007, along with the SWAMPS equivalent information (Fig. 1b), for comparison with GLWD (Fig. 1c). Even at this scale, large differences are evident between the three datasets. GIEMS and GLWD show much larger inland water fractions than SWAMPS. GLWD has particularly large inundation extent in Canada, where many small lakes are located. The major large river floodings (e.g., Amazon, Orinoco, and GangesBrahmaputra) appear clearly on both GIEMS and GLWD maps. The large water fraction in SWAMPS is concentrated on the coastal region (see, e.g., Indonesia). That is very likely related to the contamination of the retrieval by the ocean. Close to the coast, part of the energy observed by the microwave instruments can 


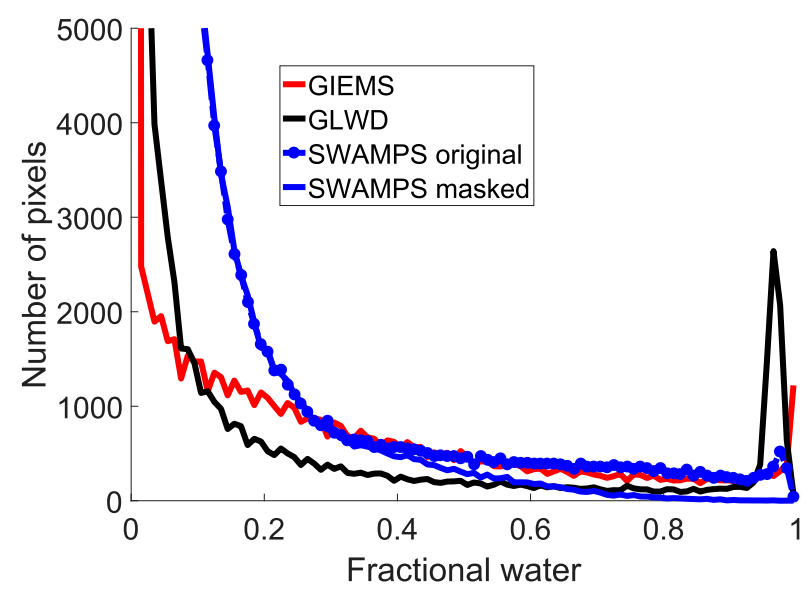

FIG. 2. Histograms of long-term max fractional water surfaces for the four datasets in Fig. 1.

come from the ocean, and the signal can be misinterpreted as coming from terrestrial inundated surfaces, if a careful filtering is not applied. Here we propose to filter the SWAMPS data to eliminate the ocean contamination close to the coast. Figure 1d represents the SWAMPS data where the contaminated coastal pixels are masked. SWAMPS also detects water almost everywhere on the globe, even in the North African desert. Histograms of the maximum fractional water surface are presented in Fig. 2 for the four datasets in Fig. 1. GLWD shows a large number of highly inundated pixels ( $>90 \%)$, mostly located in Canada (see Fig. 1c). SWAMPS has a very large number of fractional water surfaces below 0.2 , much more than the two other datasets. However, it has much less large water fractions, especially after filtering of the coasts.

For each pixel and each satellite-derived dataset, the mean fractional inundation at annual maximum and minimum has been calculated, along with the mean yearly amplitude of the fractional inundation (Fig. 3; note that for SWAMPS the coastal filtering is applied). Maps of the differences of these values between GIEMS and SWAMPS data are also presented. Compared to GIEMS, SWAMPS shows very limited amplitude in the annual cycle of the inundation, even in regions where large seasonal variations are expected.

Time series of the surface water from GIEMS and SWAMPS are compared globally and for three latitude bands [tropical $\left(30^{\circ} \mathrm{S}-30^{\circ} \mathrm{N}\right)$, midlatitude $\left(30^{\circ}-55^{\circ} \mathrm{N}\right)$, and boreal $\left.\left(55^{\circ}-70^{\circ} \mathrm{N}\right)\right]$ in Fig. 4, along with the corresponding values from GLWD, from the Matthews and Fung (1987) wetland dataset, and from the irrigated fields from MIRCA. GLWD (black) shows the maximum level of surface water both globally $\left(\sim 13 \times 10^{6} \mathrm{~km}^{2}\right)$ and regionally. This is expected as it is representative of the maximum inundation and it has a better spatial resolution than the Matthews and Fung (1987) dataset (that is also expected to present the maximum inundation, but with a much lower spatial resolution and thus likely to miss the small water surfaces). The Matthews and Fung (1987) dataset (cyan) has much less water extent in the boreal and the midlatitude regions, as it is representative of the wetlands only and does not include the lakes and rivers $\left(\sim 5.3 \times 10^{6} \mathrm{~km}^{2}\right)$. The maximum global surface water extent derived from

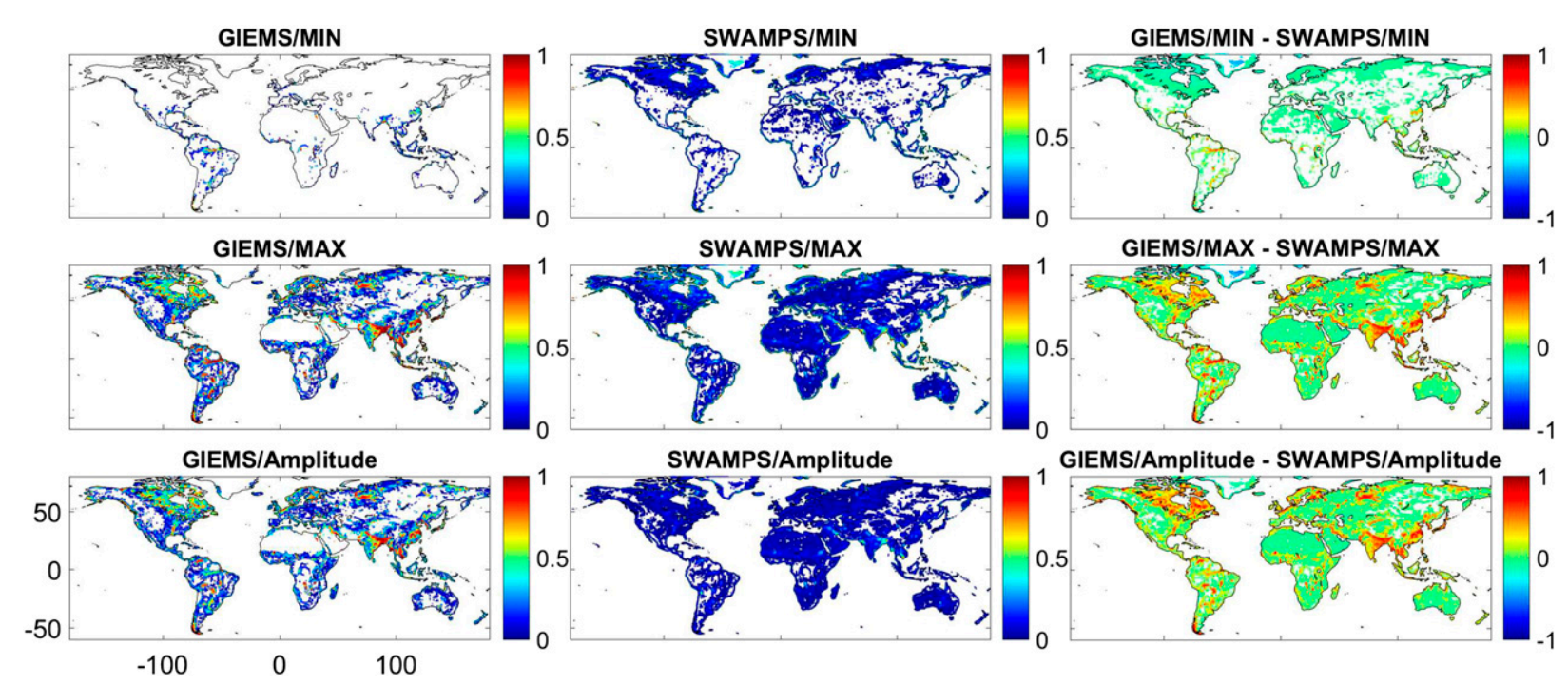

FIG. 3. Global-mean annual (top) min and (middle) max of the fractional inundation and (bottom) amplitude for (left) GIEMS, (center) SWAMPS, and (right) their differences. The information is presented on the $773 \mathrm{~km}^{2}$ equal-area grid. 

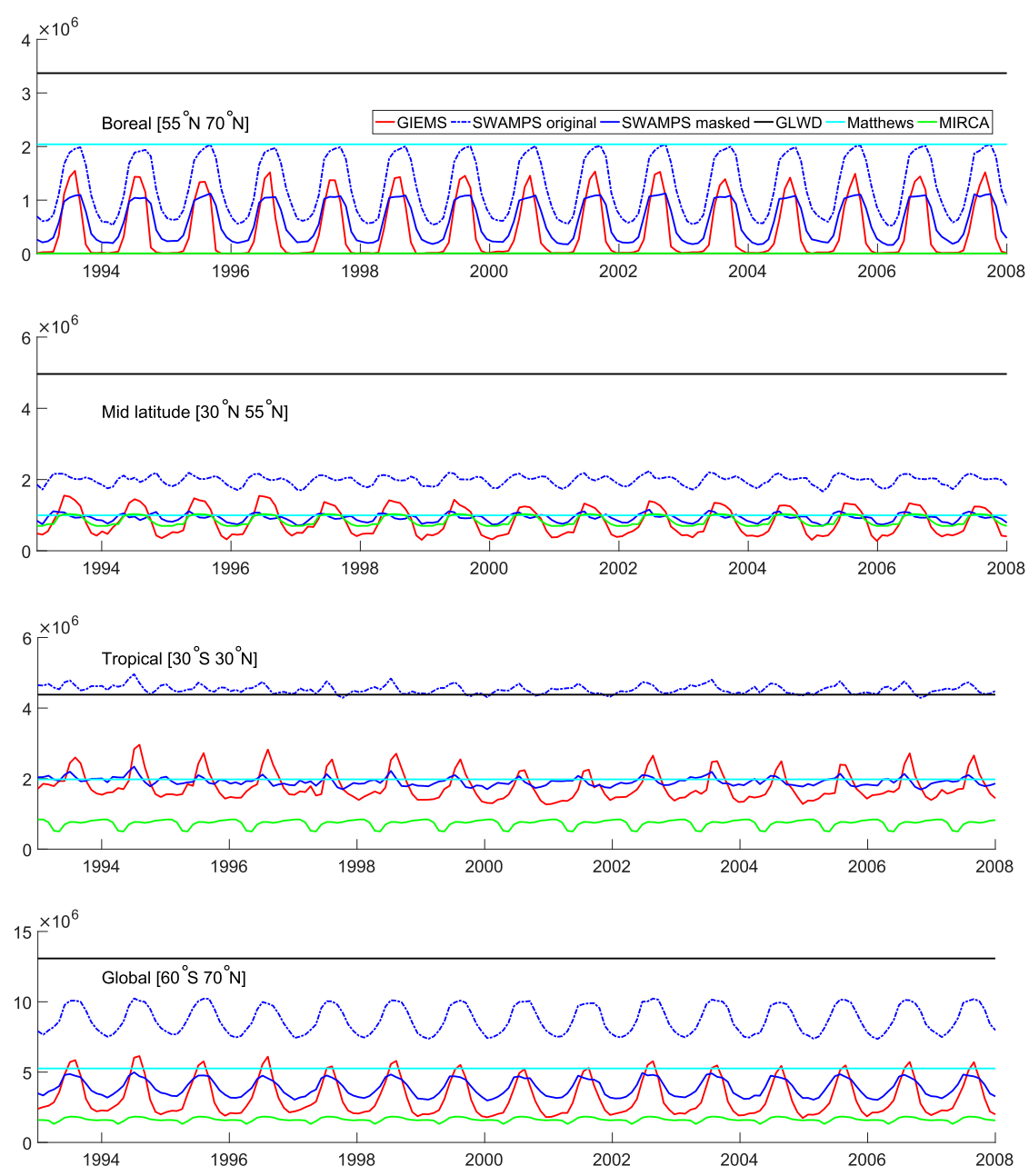

FIG. 4. Time series of surface water extent derived from GIEMS (red), original SWAMPS (dashed blue), SWAMPS with coastal filtering (blue), GLWD (black), Matthews and Fung (1987) dataset (cyan), and MIRCA irrigated fields (green), at three latitude bands and globally, for the period 1993-2007.

GIEMS is $\sim 6.2 \times 10^{6} \mathrm{~km}^{2}$, smaller than that derived from GLWD. From comparison with high-resolution SAR estimates over the Amazon basin, the accuracy of the GIEMS product has been estimated at $10 \%$ of the $773 \mathrm{~km}^{2}$ equal-area grid: because of the low-spatialresolution satellite sensors, GIEMS tends to miss the small water fraction below $10 \%$ of the pixels or to overestimate the large inundation fraction above $90 \%$ (Prigent et al. 2007). However, this problem is partly corrected in GIEMS-D15 (Fluet-Chouinard et al. 2015), which merges GIEMS low-inundated pixels with GLWD. The maximum of the original SWAMPS inundation extent at global scale $\left(\sim 10.3 \times 10^{6} \mathrm{~km}^{2}\right)$ is close to the GLWD extent, as mentioned in Schroeder et al. (2015). Over the tropical region, the maximum surface water derived from the original SWAMPS (dashed blue) is very close to that of GWLD (black), $\sim 4.9 \times 10^{6}$ and $\sim 4.4 \times 10^{6} \mathrm{~km}^{2}$, respectively. However, it is surprising to observe that the global maximum value is reduced to $\sim 5 \times 10^{6} \mathrm{~km}^{2}$ (i.e., a reduction of nearly $51 \%$ ) when the coasts are filtered out. Over the tropical region, SWAMPS decreases by nearly $53 \%$ after coastal masking to reach $\sim 2.3 \times 10^{6} \mathrm{~km}^{2}$. The original SWAMPS dataset detects more water surfaces than GIEMS for all three latitude bands. After coastal filtering, the yearly-mean temporal SWAMPS water surface extent is similar to the GIEMS one, but the seasonal amplitude of SWAMPS is much lower than the GIEMS one. Table 1 shows monthly long-term minimum, longterm maximum, and long-term mean, as well as seasonal amplitude between monthly long-term maximum and minimum of surface water extent derived from GIEMS and SWAMPS after coastal filtering globally, and at three latitude bands, for the studied period (1993-2007). 
TABLE 1. Monthly long-term min, long-term max, long-term mean, and seasonal amplitude between monthly long-term max and min of surface water extent derived from GIEMS and SWAMPS after coastal filtering at three latitude bands and globally, for the period $1993-2007$. Unit is $\times 10^{6} \mathrm{~km}^{2}$.

\begin{tabular}{lcccc}
\hline & Min & Max & Mean & Amplitude \\
\hline Boreal & & & & \\
$\quad$ GIEMS & 0.0 & 1.5 & 0.4 & 1.5 \\
$\quad$ SWAMPS & 0.2 & 1.2 & 0.6 & 1.0 \\
Midlatitude & & & & \\
$\quad$ GIEMS & 0.3 & 1.6 & 0.8 & 1.3 \\
$\quad$ SWAMPS & 0.7 & 1.2 & 0.9 & 0.5 \\
Tropical & & & & \\
$\quad$ GIEMS & 1.3 & 3.0 & 1.8 & 1.7 \\
$\quad$ SWAMPS & 1.7 & 2.3 & 1.9 & 0.6 \\
Global & & & & \\
$\quad$ GIEMS & 1.7 & 6.2 & 3.2 & 4.5 \\
$\quad$ SWAMPS & 3.0 & 5.0 & 3.9 & 2.0 \\
\hline
\end{tabular}

Long-term mean values between GIEMS and SWAMPS are close, but GIEMS shows larger amplitude than SWAMPS regionally and globally. From Fig. 4 we can see that wetland surfaces derived from GIEMS (red) and SWAMPS (dashed blue) have strong temporal correlations globally (92\%) and over the boreal region $(88 \%)$, but lower temporal correlations over midlatitudes $(58 \%)$ and the tropics $(48 \%)$. Furthermore, in these two regions, GIEMS has a much stronger seasonal cycle than SWAMPS.

In the rest of the study, the coastal filter is applied to the SWAMPS data.

\section{b. Basin-scale comparisons}

\section{1) Comparisons over the Amazon BAsin}

The Amazon basin is the largest drainage basin in the world with the largest discharge, and it is mostly located in the tropical rain forest. Figure 5 shows the long-term maximum inundation maps (1993-2007) over the Amazon basin, derived from the different wetland datasets. Spatial distributions of surface water datasets are similar. Although the spatial correlation between long-term maximum inundated maps of GIEMS and SWAMPS is nearly $90 \%$, SWAMPS fractional surface water is much lower than the GIEMS and GLWD ones. In Schroeder et al. (2015), it is noted that SWAMPS has problems detecting water underneath dense forest canopy. The ability of passive microwaves to detect surface water below dense forest was demonstrated early by Giddings and Choudhury (1989) or Sippel et al. (1994) in their pioneer works. It is rather surprising that SWAMPS cannot detect these surface waters. GIEMS-D15 corrects GIEMS by adding the small surface water fractions that are likely
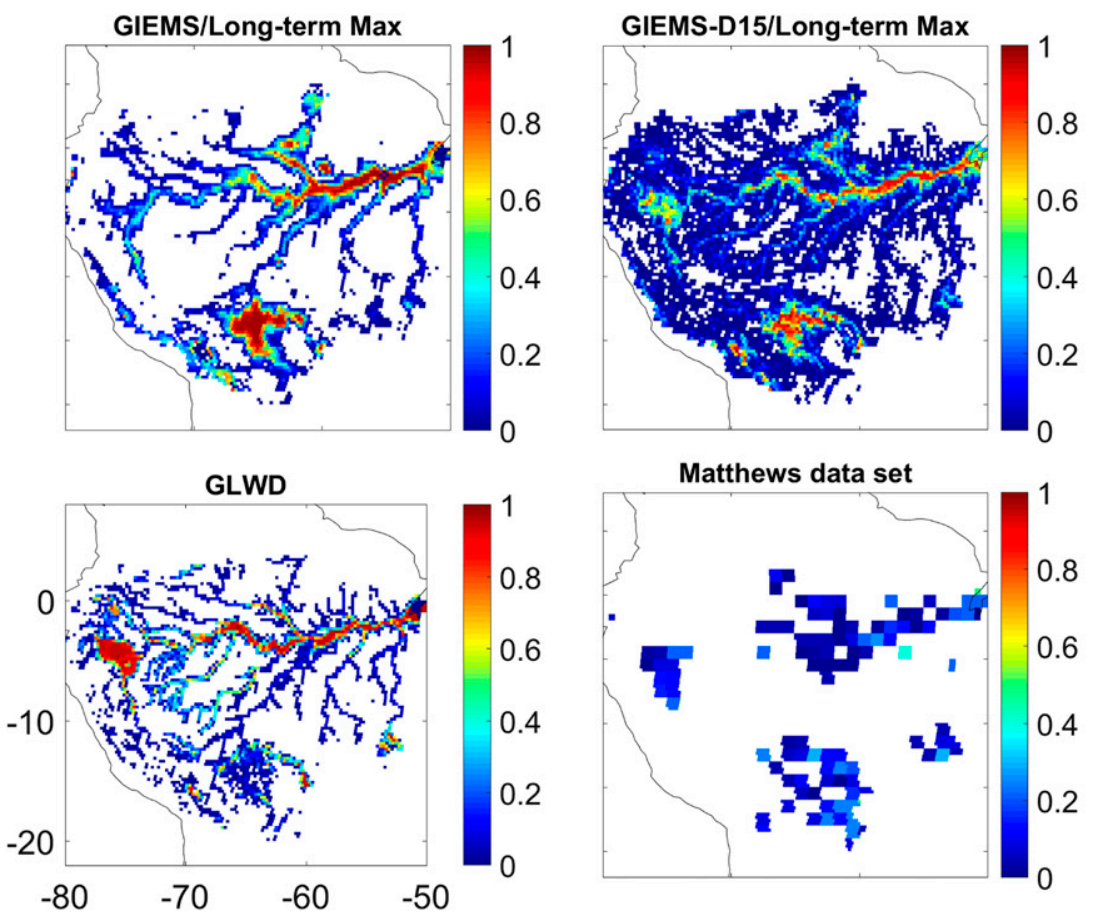

SWAMPS/Long-term Max

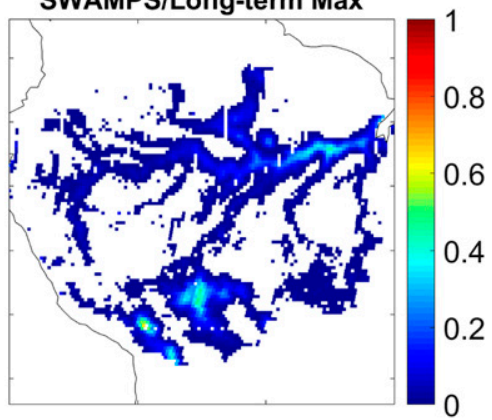

FIG. 5. Long-term max inundation maps averaged over 1993-2007 from GIEMS and SWAMPS, and max inundation maps from the different surface water datasets over the Amazon basin. Shown are GIEMS, GIEMS-D15, SWAMPS, GLWD, and Matthews and Fung (1987) datasets. 

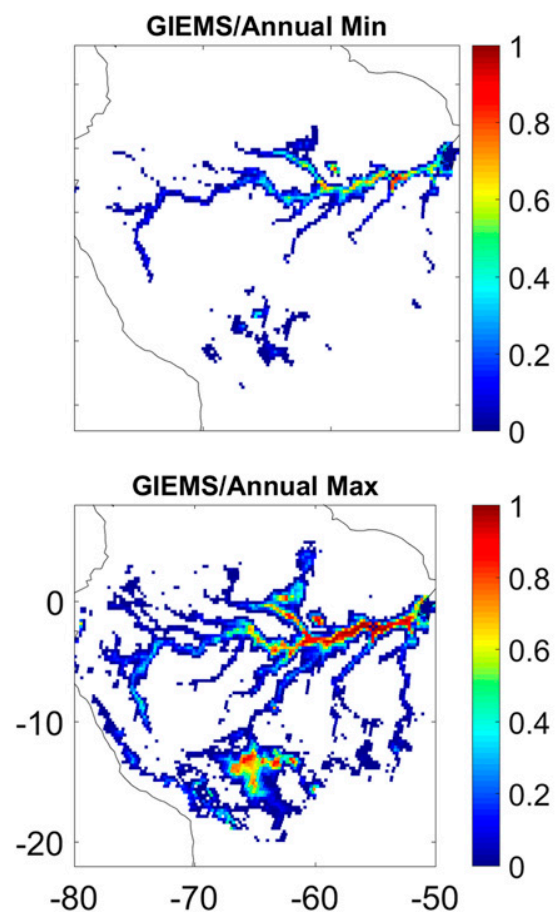

FIG. 6. Mean annual (top) min and (bottom) max of the inundation derived from different surface water datasets over the Amazon basin

for (left) GIEMS, (center) GIEMS-D15, and (right) SWAMPS.
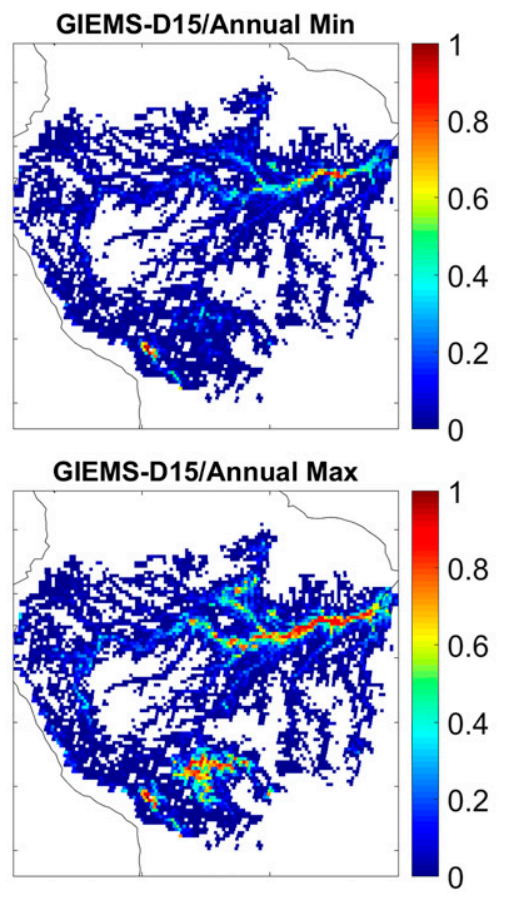

SWAMPS/Annual Min

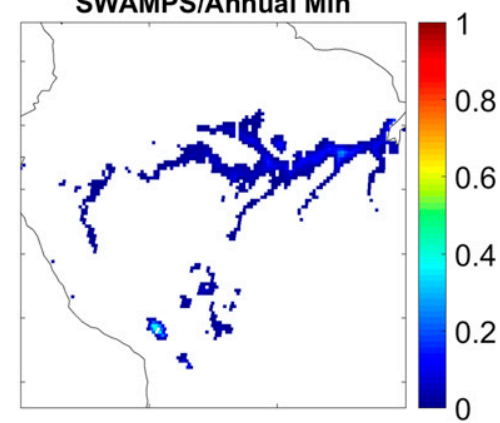

SWAMPS/Annual Max

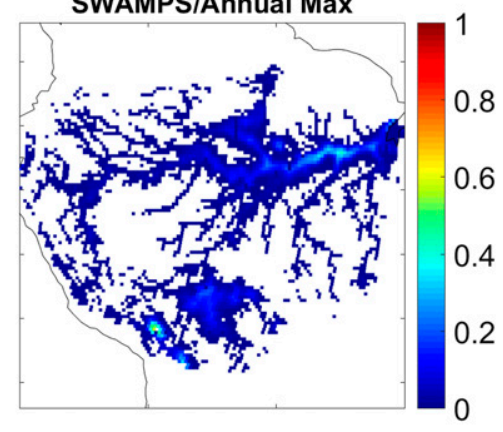

missed by GIEMS, and this is clearly seen when comparing GIEMS and GIEMS-D15 inundation maps in Fig. 5.

Mean annual minimum and maximum inundation maps of GIEMS, GIEMS-D15, and SWAMPS are shown in Fig. 6. Similar to the long-term maximum inundated maps, the spatial distributions of the GIEMS and SWAMPS datasets are similar (spatial correlation of $80 \%$ and $90 \%$ for the minimum and maximum, respectively), but SWAMPS detects much less surface water than the two GIEMS versions.

Monthly time series of the surface water extents have been calculated over the basin, along with the river discharge at the mouth of the river (Fig. 7, top). The monthly-mean annual cycle from January to December
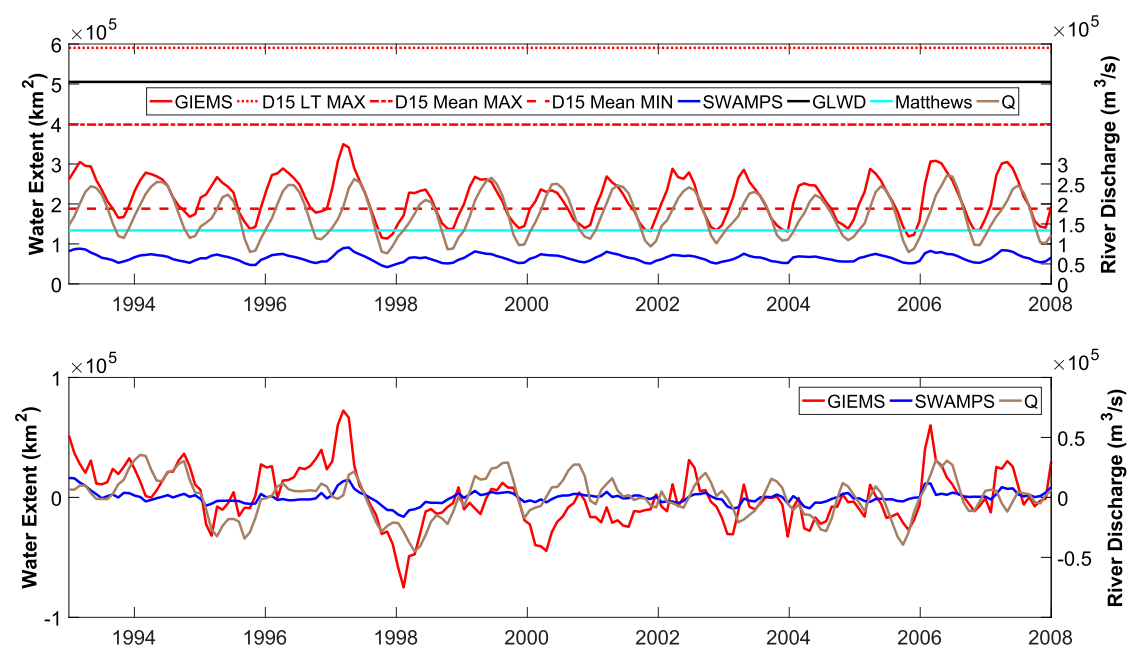

FIG. 7. (top) Time series and (bottom) anomaly of surface water extent derived from the different wetland datasets, along with the river discharge over the Amazon basin from 1993 to 2007. Anomaly is calculated by removing the monthly-mean annual cycle from time series. 
TABLE 2. Time series and anomaly correlations between GIEMS, SWAMPS, and river discharge $Q$ over the Amazon basin for the period 1993-2007. Numbers in parentheses are calculated with 1-month lag between GIEMS/SWAMPS and $Q$.

\begin{tabular}{lll}
\hline \hline & $\begin{array}{l}\text { Time series } \\
\text { correlation }\end{array}$ & $\begin{array}{c}\text { Anomaly } \\
\text { correlation }\end{array}$ \\
\hline GIEMS $/$ SWAMPS & $95 \%$ & $77 \%$ \\
GIEMS $/ Q$ & $78 \%(91 \%)$ & $54 \%(58 \%)$ \\
SWAMPS $/ Q$ & $74 \%(88 \%)$ & $57 \%(61 \%)$ \\
\hline
\end{tabular}

is computed by averaging values from all Januaries to Decembers between 1993 and 2007. Then these values are subtracted from the time series for each given month, to obtain the anomaly time series (Fig. 7, bottom). Time series and anomaly correlations are shown in Table 2. The behaviors of time series of GIEMS (red) and SWAMPS (blue) are very similar to that of the river discharge (brown), with very high correlations. Time series correlation between GIEMS and SWAMPS is $95 \%$. It is $78 \%$ and $74 \%$ with the river discharge for GIEMS and SWAMPS, respectively. Time series correlations with the river discharge increase when calculated with 1-month lag, as expected, reaching $91 \%$ and $88 \%$, respectively. The anomaly correlation between GIEMS and SWAMPS is surprisingly high $(77 \%)$. The same analysis has been carried out over the Orinoco basin, showing a correlation of $99 \%$ between time series of GIEMS and SWAMPS and a correlation of $97 \%$ between their anomalies. More details can be found in the supplemental material.

\section{2) COMPARISONS OVER THE NIGER BASIN}

The Niger basin is characterized by a large inner delta that results in a region of braided streams and has marked seasonal floods. Long-term maximum inundation maps are shown over the Niger basin in Fig. 8, while their minimum and maximum are presented in Fig. 9, and Fig. 10 shows their time series and anomalies, as well as that derived from the river discharge data. Time series and anomaly correlations between GIEMS/ SWAMPS and other ancillary datasets are shown in Table 3. Time series of GIEMS and SWAMPS are in opposite phase (Fig. 10), making the time series correlation negative $(-40 \%)$. Again, GIEMS shows a much stronger seasonal cycle than SWAMPS over this basin. GIEMS and the river discharge (brown) show similar behavior with a time series correlation of nearly $81 \%$ (for the common period 1998-2005). In contrast, SWAMPS does not show the same seasonal cycle, making its time series correlation with the river discharge negative $(-60 \%)$. Note that other studies

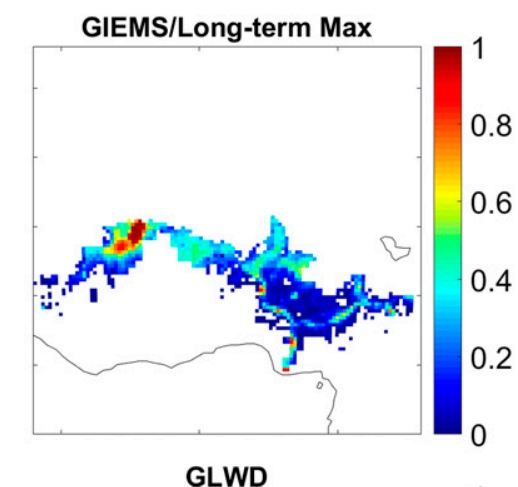

GIEMS-D15/Long-term Max

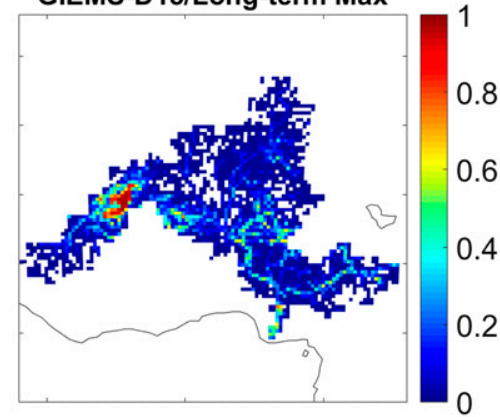

Matthews data set

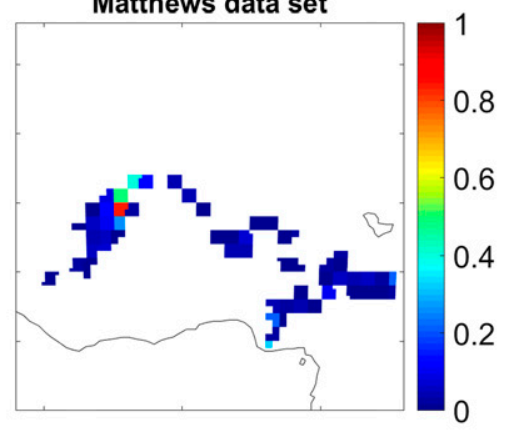

8
SWAMPS/Long-term Max

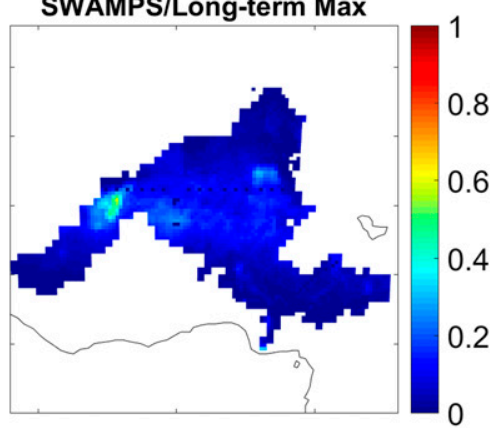

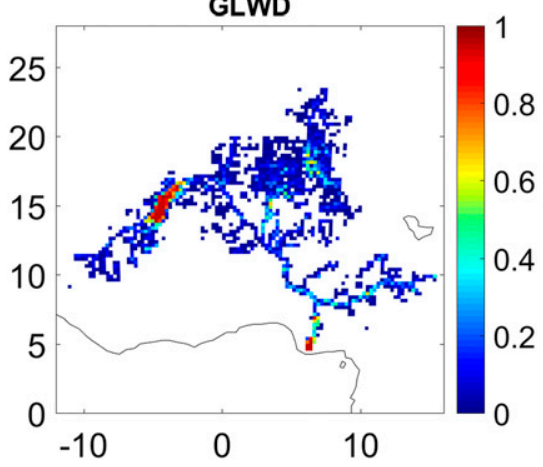

FIG. 8. Long-term max inundation maps averaged over 1993-2007 from GIEMS and SWAMPS, and max inundation maps from the different surface water datasets over the Niger basin. Shown are the GIEMS, GIEMS-D15, SWAMPS, GLWD, and Matthews and Fung (1987) datasets. 

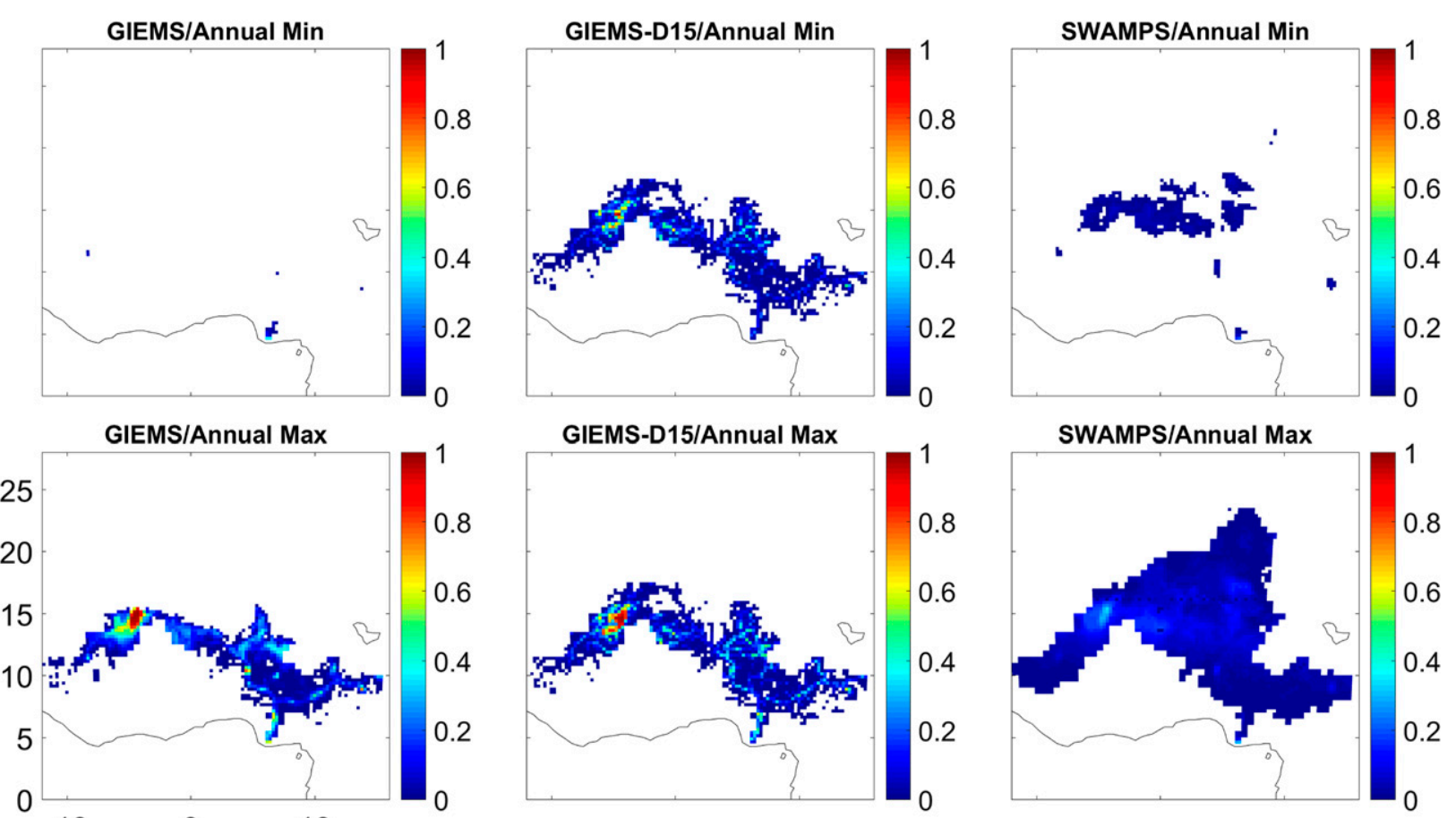

FIG. 9. Mean annual (top) min and (bottom) max of the inundation derived from different surface water datasets over the Niger basin for (left) GIEMS, (center) GIEMS-D15, and (right) SWAMPS.

analyzed GIEMS over the Niger region, for example, Pedinotti et al. (2012) or Aires et al. (2014). Pedinotti et al. (2012) evaluate the ability of the ISBA-Total Runoff Integrating Pathways (TRIP) continental hydrologic system to represent key processes (surface water, rivers and floodplain dynamics, and water storage) related to the hydrological cycle of the Niger basin.
To this end, GIEMS is used to evaluate the long-term simulations that showed that the flooding scheme leads to a nonnegligible increase of evaporation over large flooded areas, which in turns improved the Niger River discharge estimates at several locations. The objective of Aires et al. (2014) is to develop downscaling methodologies to obtain a long time record of inundation extent over
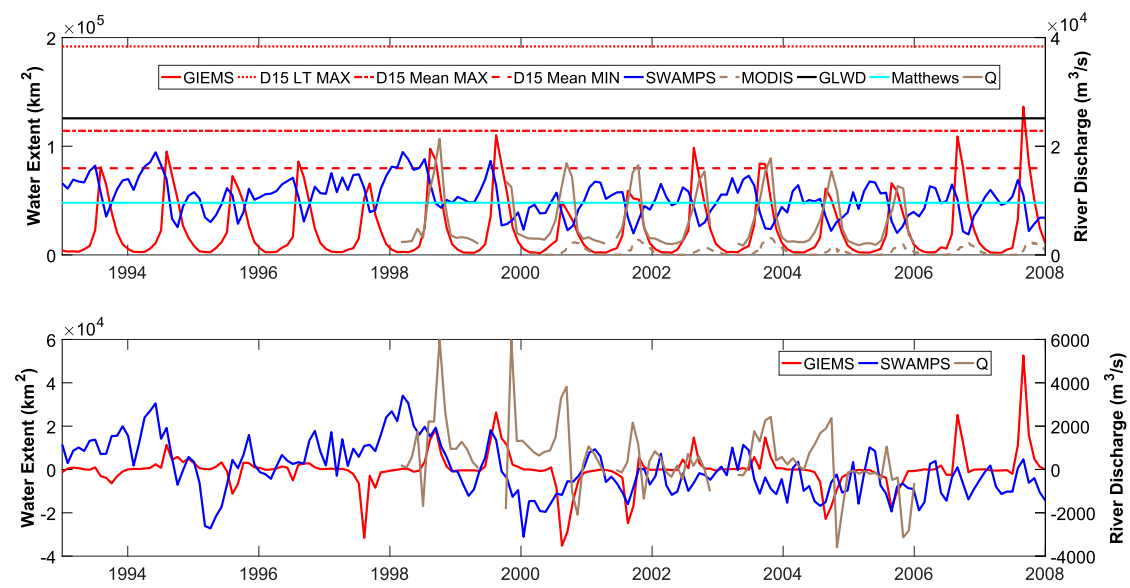

FIG. 10. (top) Time series and (bottom) anomaly of surface water extent derived from the different wetland datasets (1993-2007), along with the river discharge (1998-2005) over the whole Niger basin. MODIS surface water extent time series for the inner delta only (dashed brown) is available from 2000. 
TABLE 3. Time series and anomaly correlations between GIEMS, SWAMPS, and river discharge $Q$ over the Niger basin for the period 1993-2007. Numbers in parentheses are calculated with 2-month lag between GIEMS/SWAMPS and $Q$.

\begin{tabular}{lcc}
\hline \hline & $\begin{array}{c}\text { Time series } \\
\text { correlation }\end{array}$ & $\begin{array}{c}\text { Anomaly } \\
\text { correlation }\end{array}$ \\
\hline GIEMS $/$ SWAMPS & $-40 \%$ & $20 \%$ \\
GIEMS $Q$ & $81 \%(51 \%)$ & $-3 \%(44 \%)$ \\
SWAMPS $/ Q$ & $-60 \%(10 \%)$ & $-2 \%(12 \%)$ \\
\hline
\end{tabular}

the inner Niger delta at high spatial resolution $(500 \mathrm{~m})$ based on the existing low-spatial-resolution results of the GIEMS dataset and observations from MODIS.

Time series of the surface water derived from MODIS visible images over the Niger basin for the period 2000-07 (Bergé-Nguyen and Crétaux 2015) were also compared to the behavior of GIEMS and SWAMPS over this region. From Fig. 10 (top) and Fig. 11, it is clear that GIEMS and MODIS surface water time series have similar seasonal dynamics over the common period (2000-07). However, GIEMS has a higher maximum value than MODIS, which could suggest an overestimation from GIEMS over this region. In addition, the interannual variability is not totally similar between GIEMS and MODIS. Similar passive microwave signatures can be observed over arid regions and over water: these two surface types have low emissivities with rather large emissivity polarization differences. As a consequence, reliable and accurate detection of surface water in arid and semiarid regions is not trivial. In GIEMS, NDVI information is used in the process to help solve these ambiguities. SWAMPS obviously encounters difficulties in this type of environment, with false detection of water in deserts and underestimation of water surfaces in inundated deltas. This is in agreement with Schroeder et al. (2015). As a result, over the Niger delta, SWAMPS does not capture at all the water surface dynamics.

\section{3) COMPARISONS OVER THE OB BASIN}

The Ob basin in western Siberia is selected to represent the boreal environments. SWAMPS surface waters are again much less extended than the other estimates (see Figs. 12 and 13). SWAMPS surface water peaks generally in May, one month earlier than GIEMS. Time series correlation between GIEMS (SWAMPS) and the river discharge for the studied period is $91 \%$ (62\%). When calculated with 1-month lag, time series correlation decreases for GIEMS to $80 \%$, while it increases for SWAMPS to $91 \%$ (Table 4). The same conclusions can be found for the anomaly correlations between GIEMS, SWAMPS, and river discharge over the Ob basin (also Table 4). The lag between GIEMS and SWAMPS could be partly related to differences in the snow filtering performed monthly with GIEMS and daily with SWAMPS. GIEMS estimates are flagged too quickly by the NSIDC snow mask, so we are missing the end of the high-waterstage season (September-October). The river discharge from the $\mathrm{Ob}$ River and GIEMS have been compared in Papa et al. (2008b), and the use of the snow mask was well discussed. The snow flag in GIEMS is under analysis and will be refined for the next version of the dataset.

\section{Discussion}

As already observed in Fig. 1, the maximum surface water extent estimated by SWAMPS for the major basins is limited compared to the other estimates. The annual maximum SWAMPS surface extent (including

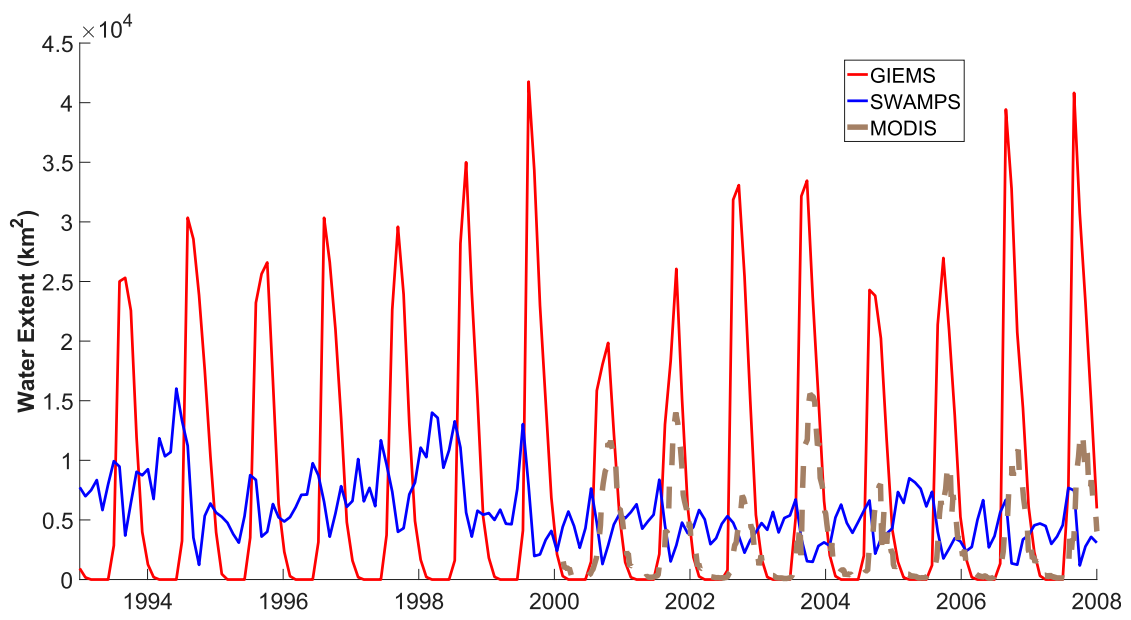

FIG. 11. Time series of surface water extent derived from GIEMS, SWAMPS, and MODIS for the inner Niger delta. 


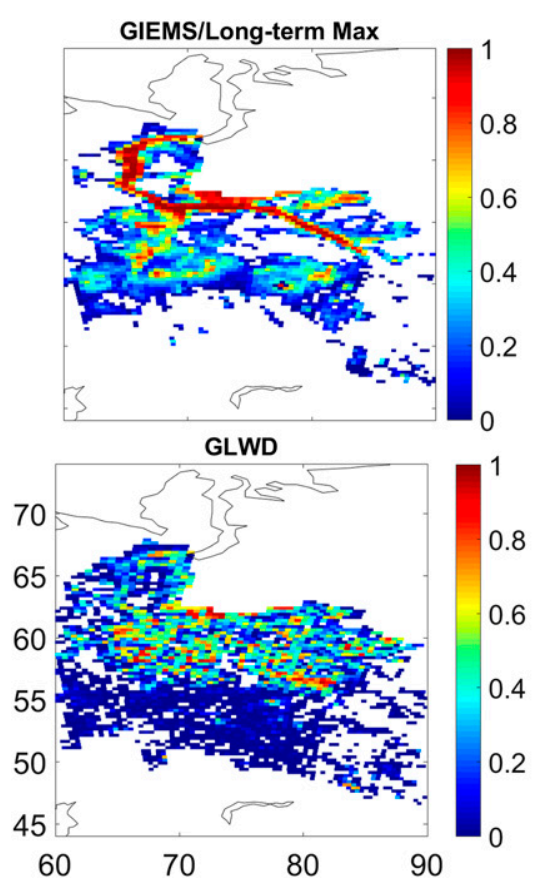

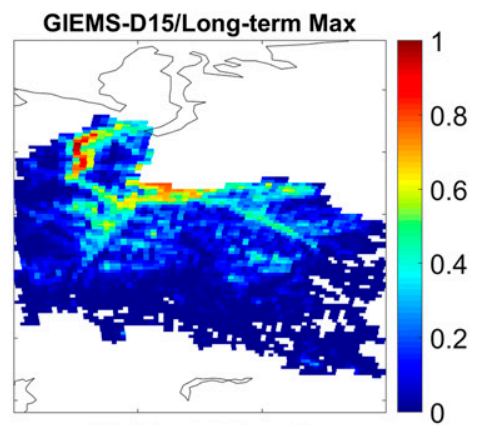

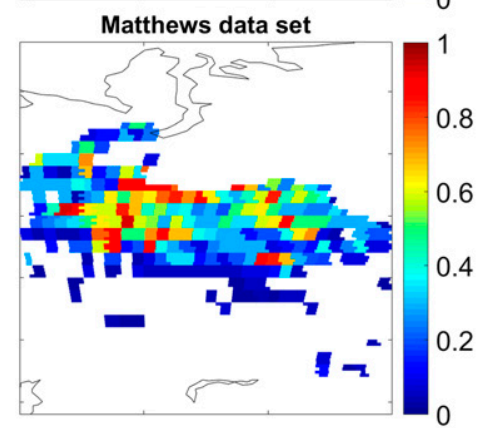

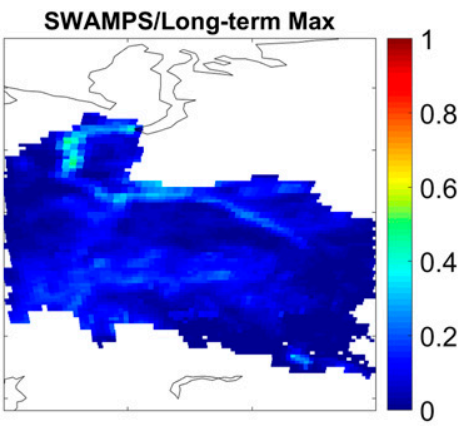

FIG. 12. Long-term max inundation maps averaged over 1993-2007 from GIEMS and SWAMPS, and max inundation maps from the different surface water datasets over the Ob basin. Shown are the GIEMS, GIEMS-D15, SWAMPS, GLWD, and Matthews and Fung (1987) datasets.

the coasts) and the GLWD surfaces are similar, and this feature is advertised in Schroeder et al. (2015). However, $\sim 50 \%$ of the surface water with SWAMPS is located along the coasts. This clearly relates to contamination by the ocean in the observation fields of view of the passive microwave observations and to the lack of adequate filtering in the retrieval algorithm. The SWAMPS algorithm fits the global maximum water extent of GLWD, but as the coastal waters were mistakenly included in the tuning, the inland water extent is therefore strongly underestimated. The range of seasonal variability of SWAMPS is also strongly reduced because coastal regions do not evolve in time.

The underestimation of the SWAMPS extent under dense vegetation is particularly significant, as observed in the Amazon basin. The well-established SAR estimate from Hess et al. (2003) is $243000 \mathrm{~km}^{2}$ at the high stage, very close to the GIEMS values, and very
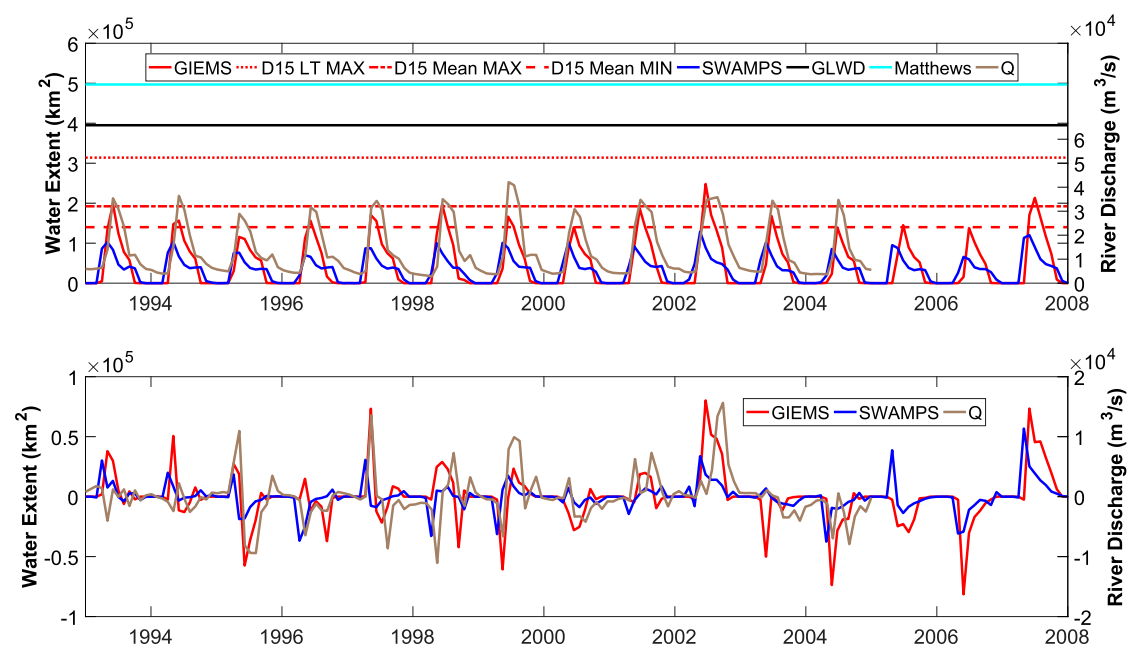

FIG. 13. As in Fig. 7, but for the Ob basin. River discharge (brown) is available until 2004. 
TABLE 4. Time series and anomaly correlations between GIEMS, SWAMPS, and river discharge $Q$ over the Ob basin for the period 1993-2007. Numbers in parentheses are calculated with 1-month lag between GIEMS/SWAMPS and $Q$.

\begin{tabular}{lll}
\hline \hline & $\begin{array}{l}\text { Time series } \\
\text { correlation }\end{array}$ & $\begin{array}{c}\text { Anomaly } \\
\text { correlation }\end{array}$ \\
\hline GIEMS/SWAMPS & $70 \%$ & $38 \%$ \\
GIEMS $/ Q$ & $91 \%(80 \%)$ & $49 \%(40 \%)$ \\
SWAMPS $/ Q$ & $62 \%(91 \%)$ & $28 \%(59 \%)$ \\
\hline
\end{tabular}

different from the Phased Array type L-band Synthetic Aperture Radar (PALSAR) estimates $\left(40000 \mathrm{~km}^{2}\right)$ provided by Schroeder et al. (2015) in their paper.

In the microwaves, the surface emissivities of water and desert surfaces are both rather low, with large polarization differences. As a consequence, there can be confusion between deserts and surface waters from passive microwave observations. This is typically what happens over deserts with SWAMPS, with anomalous detection of surface water over arid regions. In GIEMS, the systematic use of visible and near-infrared observations helps suppress these ambiguities.

Figure 14 (top) shows the time correlation between the two datasets and Fig. 14 (bottom) shows the time correlation between their anomalies, for the major 23 river basins in the world. The correlation is important for most basins, for the time series as well as for their anomalies. It is even very high for some tropical basins (Orinoco and Mekong). This tends to confirm the seasonal variations of the surface water estimates, despite their different seasonal amplitudes. Note that correlations on time series or anomalies can be high despite large bias errors.

Over Asia (i.e., northeastern India and Bangladesh), GIEMS estimates large surface water extents that are related partly to rice paddies (see the MIRCA estimation of the rice paddies extent over the tropical region in Fig. 4). It is also suspected that GIEMS is very sensitive to saturated soil in this region, and as a consequence might overestimate the surface water extent in these regions.

\section{Conclusions}

Two global satellite-derived surface water datasets are compared on a monthly-mean basis from 1993 to 2007 (GIEMS and SWAMPS), along with two widely used static maps of the surface water. The 23 largest basins in the world have been studied, and three basins representative of different environments (the Amazon basin in the tropics, the Niger basin in a semiarid environment, and the $\mathrm{Ob}$ River in the boreal region) have been presented. Although they are based on similar observations, mainly passive and active microwaves, the satellite-derived datasets show large differences, globally and regionally, in terms of surface extents both at minimum and maximum inundation in the year. The
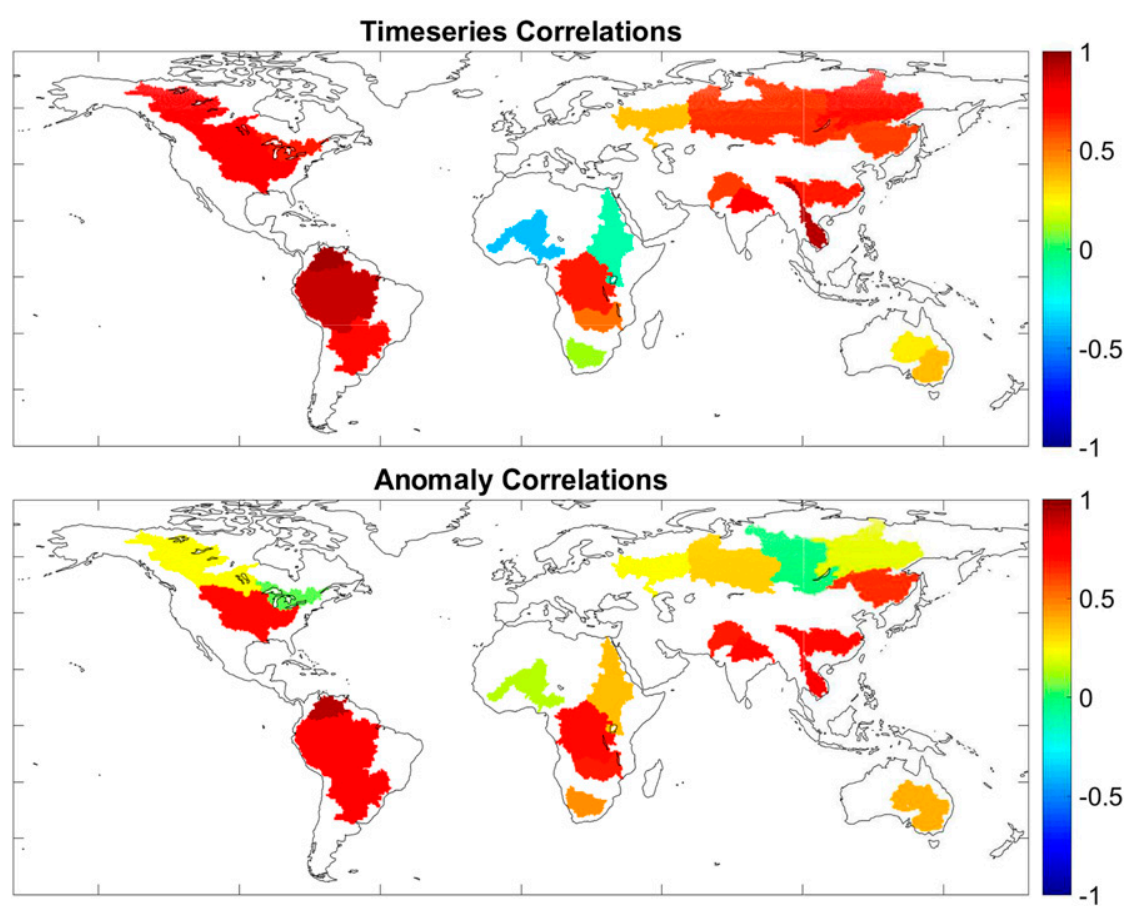

FIG. 14. Basinwide global (top) time series and (bottom) anomaly correlations for the 23 largest basins in the world between GIEMS and SWAMPS datasets. 
global maximum inundation extent over 1993-2007 is $\sim 6.2 \times 10^{6} \mathrm{~km}^{2}$ for GIEMS and $\sim 10.3 \times 10^{6} \mathrm{~km}^{2}$ for SWAMPS, compared to $\sim 13 \times 10^{6} \mathrm{~km}^{2}$ for GLWD and $\sim 5.3 \times 10^{6} \mathrm{~km}^{2}$ for the Matthews and Fung (1987) wetland dataset. Approximately $50 \%$ of the SWAMPS inundated surfaces are located along the coast at the maximum annual inundation. This is clearly related to contamination by the ocean in the observation fields of view. Once this problem is filtered out, the long-term maximum surface water from SWAMPS is reduced to $\sim 5 \times 10^{6} \mathrm{~km}^{2}$. Globally and for the studied basins, the annual amplitude of the inundation extent is very limited in SWAMPS compared to GIEMS (47\% lower). Despite their large difference in the seasonal amplitude, GIEMS and SWAMPS have similar temporal dynamics for most parts of the globe. Over the Amazon basin, GIEMS and SWAMPS show a very high temporal correlation $(95 \%)$, but with SWAMPS maximum extent is half the size of that observed with GIEMS and with previous SAR estimates. Over the Niger basin, SWAMPS seasonal cycle is out of phase with both GIEMS and MODIS-derived estimates, as well as with river discharge data. This confirms the fact that SWAMPS fails to capture the seasonal dynamic of wetlands here. GIEMS and MODIS surface water time series agree in the seasonal variability, but GIEMS water extent is significantly larger than the MODIS one. In the $\mathrm{Ob}$ region, the different snow detection method could explain part of the difference in the seasonal cycle.

A clear advantage of the SWAMPS dataset today is its longer time period, up to 2013. The current version of the GIEMS algorithm requires a large quantity of ancillary satellite products to run, including outputs from the GEWEX International Satellite Cloud Climatology Project (Rossow and Schiffer 1999) that stopped in 2008. Efforts are underway to extend the GIEMS time series to current times, to provide the community with a long time record of carefully evaluated surface water extent all over the globe, using a reduced number of ancillary parameters for more robustness.

Acknowledgments. We thank our colleagues for providing ancillary datasets for this work. We thank two anonymous reviewers for their suggestions and comments. This study was financially supported by a $\mathrm{PhD}$ fellowship from the Vietnam International Education Development (911 project).

\section{REFERENCES}

Adam, L., P. Döll, C. Prigent, and F. Papa, 2010: Global-scale analysis of satellite-derived time series of naturally inundated areas as a basis for floodplain modeling. Adv. Geosci., 27, 45-50, doi:10.5194/adgeo-27-45-2010.
Aires, F., F. Papa, C. Prigent, J.-F. Crétaux, and M. BergéNguyen, 2014: Characterization and space-time downscaling of the inundation extent over the inner Niger delta using GIEMS and MODIS data. J. Hydrometeor., 15, 171-192, doi:10.1175/JHM-D-13-032.1.

_- L. Miolane, C. Prigent, E. Fluet-Chouinard, B. Lerner, and F. Aires, 2017: A global dynamic long-term inundation extent dataset at high spatial resolution derived through downscaling of satellite observations. J. Hydrometeor., doi:10.1175/JHM-D-16-0155.1, in press.

Alsdorf, D. E., E. Rodriguez, and D. P. Lettenmaier, 2007: Measuring surface water from space. Rev. Geophys., 45, RG2002, doi:10.1029/2006RG000197.

Bergé-Nguyen, M., and J.-F. Crétaux, 2015: Inundations in the inner Niger delta: Monitoring and analysis using MODIS and global precipitation datasets. Remote Sens., 7, 21272151, doi:10.3390/rs70202127.

Bousquet, P., and Coauthors, 2006: Contribution of anthropogenic and natural sources to atmospheric methane variability. Nature, 443, 439-443, doi:10.1038/nature05132.

Bridgham, S. D., H. Cadillo-Quiroz, J. K. Keller, and Q. Zhuang, 2013: Methane emissions from wetlands: Biogeochemical, microbial, and modeling perspectives from local to global scales. Global Change Biol., 19, 1325-1346, doi:10.1111/gcb.12131.

Brodzik, M., and R. Armstrong, 2013: Northern Hemisphere EASE-Grid 2.0 weekly snow cover and sea ice extent, version 4. National Snow and Ice Data Center, Boulder, $\mathrm{CO}$, digital media. [Available online at https://nsidc.org/ data/docs/daac/nsidc0046_nh_ease_snow_seaice.gd.html.]

Chang, A., J. Foster, and D. Hall, 1987: Nimbus-7 SMMR derived global snow cover parameters. Ann. Glaciol., 9, 39-44.

Downing, J. A., and Coauthors, 2006: The global abundance and size distribution of lakes, ponds, and impoundments. Limnol. Oceanogr., 51, 2388-2397, doi:10.4319/ lo.2006.51.5.2388.

Feng, M., J. O. Sexton, S. Channan, and J. R. Townshend, 2016: A global, high-resolution $(30-\mathrm{m})$ inland water body dataset for 2000: First results of a topographic-spectral classification algorithm. Int. J. Digital Earth, 9, 113-133, doi:10.1080/ 17538947.2015.1026420.

Fluet-Chouinard, E., B. Lehner, L.-M. Rebelo, F. Papa, and S. K. Hamilton, 2015: Development of a global inundation map at high spatial resolution from topographic downscaling of coarse-scale remote sensing data. Remote Sens. Environ., 158, 348-361, doi:10.1016/j.rse.2014.10.015.

Giddings, L., and B. J. Choudhury, 1989: Observation of hydrological features with Nimbus-7 $37 \mathrm{GHz}$ data, applied to South America. Int. J. Remote Sens., 10, 1673-1686, doi:10.1080/ 01431168908903998.

Grody, N. C., and A. N. Basist, 1996: Global identification of snowcover using SSM/I measurements. IEEE Trans. Geosci. Remote Sens., 34, 237-249, doi:10.1109/36.481908.

Hess, L. L., J. M. Melack, E. M. Novo, C. C. Barbosa, and M. Gastil, 2003: Dual-season mapping of wetland inundation and vegetation for the central Amazon basin. Remote Sens. Environ., 87, 404-428, doi:10.1016/j.rse.2003.04.001.

Lehner, B., and P. Döll, 2004: Development and validation of a global database of lakes, reservoirs and wetlands. J. Hydrol., 296, 1-22, doi:10.1016/j.jhydrol.2004.03.028.

_, K. Verdin, and A. Jarvis, 2008: New global hydrography derived from spaceborne elevation data. Eos, Trans. Amer. Geophys. Union, 89, 93-94, doi:10.1029/2008EO100001. 
Matthews, E., and I. Fung, 1987: Methane emission from natural wetlands: Global distribution, area, and environmental characteristics of sources. Global Biogeochem. Cycles, 1, 61-86, doi:10.1029/GB001i001p00061.

Melton, J. R., and Coauthors, 2013: Present state of global wetland extent and wetland methane modelling: Conclusions from a model inter-comparison project (WETCHIMP). Biogeosciences, 10, 753-788, doi:10.5194/bg-10-753-2013.

Mueller, N., and Coauthors, 2016: Water observations from space: Mapping surface water from 25 years of Landsat imagery across Australia. Remote Sens. Environ., 174, 341-352, doi:10.1016/j.rse.2015.11.003.

Nakaegawa, T., 2012: Comparison of water-related land cover types in six 1-km global land cover datasets. J. Hydrometeor., 13, 649-664, doi:10.1175/JHM-D-10-05036.1.

Papa, F., C. Prigent, F. Durand, and W. B. Rossow, 2006: Wetland dynamics using a suite of satellite observations: A case study of application and evaluation for the Indian Subcontinent. Geophys. Res. Lett., 33, L08401, doi:10.1029/2006GL025767.

,$- \ldots$, and W. B. Rossow, 2007: Ob' River flood inundations from satellite observations: A relationship with winter snow parameters and river runoff. J. Geophys. Res., 112, D18103, doi:10.1029/2007JD008451.

_ - A. Güntner, F. Frappart, C. Prigent, and W. B. Rossow, 2008a: Variations of surface water extent and water storage in large river basins: A comparison of different global data sources. Geophys. Res. Lett., 35, L11401, doi:10.1029/2008GL033857.

— C. Prigent, and W. B. Rossow, 2008b: Monitoring flood and discharge variations in the large Siberian rivers from a multisatellite technique. Surv. Geophys., 29, 297-317, doi:10.1007/ s10712-008-9036-0.

,,-- F. Aires, C. Jimenez, W. B. Rossow, and E. Matthews, 2010: Interannual variability of surface water extent at the global scale, 1993-2004. J. Geophys. Res., 115, D12111, doi:10.1029/2009JD012674.

Pedinotti, V., A. Boone, B. Decharme, J. F. Crétaux, N. Mognard, G. Panthou, F. Papa, and B. A. Tanimoun, 2012: Evaluation of the ISBA-TRIP continental hydrologic system over the Niger basin using in situ and satellite derived datasets. Hydrol. Earth Syst. Sci., 16, 1745-1773, doi:10.5194/hess-16-1745-2012.

Pison, I., B. Ringeval, P. Bousquet, C. Prigent, and F. Papa, 2013: Stable atmospheric methane in the 2000s: Key-role of emissions from natural wetlands. Atmos. Chem. Phys., 13, 11609 11 623, doi:10.5194/acp-13-11609-2013.

Portmann, F. T., S. Siebert, and P. Döll, 2010: MIRCA2000—Global monthly irrigated and rainfed crop areas around the year 2000 A new high-resolution data set for agricultural and hydrological modeling. Global Biogeochem. Cycles, 24, GB1011, doi:10.1029/2008GB003435.

Prigent, C., E. Matthews, F. Aires, and W. B. Rossow, 2001: Remote sensing of global wetland dynamics with multiple satellite data sets. Geophys. Res. Lett., 28, 4631-4634, doi:10.1029/2001GL013263.
_ F. Aires, and W. B. Rossow, 2006: Land surface microwave emissivities over the globe for a decade. Bull. Amer. Meteor. Soc., 87, 1573-1584, doi:10.1175/BAMS-87-11-1573.

- , F. Papa, F. Aires, W. B. Rossow, and E. Matthews, 2007: Global inundation dynamics inferred from multiple satellite observations, 1993-2000. J. Geophys. Res., 112, D12107, doi:10.1029/2006JD007847.

,,--- C C. Jimenez, W. B. Rossow, and E. Matthews, 2012: Changes in land surface water dynamics since the 1990s and relation to population pressure. Geophys. Res. Lett., 39, L08403, doi:10.1029/2012GL051276.

— D. P. Lettenmaier, F. Aires, and F. Papa, 2016: Toward a high-resolution monitoring of continental surface water extent and dynamics, at global scale: From GIEMS (Global Inundation Extent from Multi-Satellites) to SWOT (Surface Water Ocean Topography). Surv. Geophys., 37, 339-355, doi:10.1007/s10712-015-9339-x.

Reichhardt, T., 1995: Academy under fire on wetlands definition. Nature, 375, 171, doi:10.1038/375171a0.

Ringeval, B., N. de Noblet-Ducoudre, P. Ciais, P. Bousquet, C. Prigent, F. Papa, and W. B. Rossow, 2010: An attempt to quantify the impact of changes in wetland extent on methane emissions on the seasonal and interannual time scales. Global Biogeochem. Cycles, 24, GB2003, doi:10.1029/2008GB003354.

Rossow, W. B., and R. A. Schiffer, 1999: Advances in understanding clouds from ISCCP. Bull. Amer. Meteor. Soc., 80, 2261-2287, doi:10.1175/1520-0477(1999)080<2261:AIUCFI >2.0.CO;2.

Schroeder, R., K. C. McDonald, B. D. Chapman, K. Jensen, E. Podest, Z. D. Tessler, T. J. Bohn, and R. Zimmermann, 2015: Development and evaluation of a multi-year fractional surface water data set derived from active/passive microwave remote sensing data. Remote Sens., 7, 16688-16732, doi:10.3390/rs71215843.

Sippel, S. J., S. K. Hamilton, J. M. Melack, and B. J. Choudhury, 1994: Determination of inundation area in the Amazon River floodplain using the SMMR $37 \mathrm{GHz}$ polarization difference. Remote Sens. Environ., 48, 70-76, doi:10.1016/0034-4257(94)90115-5.

Verpoorter, C., T. Kutser, D. A. Seekell, and L. J. Tranvik, 2014: A global inventory of lakes based on high-resolution satellite imagery. Geophys. Res. Lett., 41, 6396-6402, doi:10.1002/ 2014GL060641.

Vorosmarty, C. J., and Coauthors, 2010: Global threats to human water security and river biodiversity. Nature, 467, 555-561, doi:10.1038/nature09440.

Wania, R., and Coauthors, 2013: Present state of global wetland extent and wetland methane modelling: Methodology of a model inter-comparison project (WETCHIMP). Geosci. Model Dev., 6, 617-641, doi:10.5194/gmd-6-617-2013.

Yamazaki, D., M. A. Trigg, and D. Ikeshima, 2015: Development of a global $\sim 90 \mathrm{~m}$ water body map using multi-temporal Landsat images. Remote Sens. Environ., 171, 337-351, doi:10.1016/ j.rse.2015.10.014. 